\title{
Nursing Leadership Practices
}

\author{
${ }^{(1)}$ Hafiza Neelam Bibi, ${ }^{(2)}$ Sana Sehar, ${ }^{(3)}$ Muhammad Afzal, ${ }^{(4)}$ Prof. Dr. Syed Amir Gillani
}

Lahore School of Nursing, The University of Lahore, Lahore, Pakistan

\begin{abstract}
Nurses face assorted difficulties while giving the heath care offices, thus, self-assurance and solid accept on the self-capacities help them to adapt to these difficulties. In this manner, representative's confidence assumes a vital job in the effective human services administrations. In study setting it is seen that the leaders are not notable with their job and set of working responsibilities and even not with power. There for their practices are very little successful. That is the reason they can't manage their sub ordinates in formal way. Other thing in perception is dependability which not pursued extraordinarily in general human services by pioneers. Suggestions for Nursing Administration As this examination proposes, the chiefs, as saw without anyone else's input and their subordinates, respectably show uncommon authority rehearses. There is a requirement for nurture overseers to be perceptive of these practices and perceive that for unprecedented things to be cultivated in an association the five initiative practices must be displayed reliably. Consideration must be given to the present medical attendant director's development as pioneers.
\end{abstract}

Keywords: nursing, leadership

DOI: $10.7176 / \mathrm{JHMN} / 68-12$

Publication date: November $30^{\text {th }} 2019$

\section{Introduction}

Nurses face assorted difficulties while giving the heath care offices, thus, self-assurance and solid accept on the self-capacities help them to adapt to these difficulties. In this manner, representative's confidence assumes a vital job in the effective human services administrations. In addition, confidence is related with the support of head medical caretakers and it at last impacts the patient consideration (McGrath, Taenzer, Karon, \& Blike, 2016).

Leadership administrative takes practice. Initiative isn't a job that is polished once and afterward aced. Medical caretaker pioneers who experience confounded issues ought not to hurry to determine them consequently, the blend of set up administration styles is profoundly prescribed for nurture pioneers in clinical settings since different initiative styles and hypotheses are significant to nursing practice. Medical caretaker Managers and clinical pioneers ought to recognize the points of interest and disservices of every theory (Ebersole et al., 2017).

Collaborative oriented practice with the nursing staff and viable administration of individual is the patient consideration needs. Usage of the APN job brought about exceptionally positive view of correspondence between the nursing staff and the APN/medicinal group; improved correspondence of the composed arrangement of care; and learning open doors for the nursing staff (Keenan, Mutterback, Velthuizen, Pantalone, \& Gossack-Keenan, 2018).

Challenge the Process doesn't mean test the characteristics or rules, in light of the fact that firm uprightness or perfect quality are too hard to even consider evening consider living by. It doesn't mean ambushing different people when we don't agree with their considerations or points of view. Nor does it mean attempting to decimate what is working outstandingly, or trying to discard something that is only an individual trouble for you. Challenge the Process is connected to finding and completing new and better techniques for completing things to ceaselessly 
improve to create (Clinton, 2017).

Leadership vivaciously acknowledge that they can have any sort of impact. They envision the future making an ideal and unique picture of what the affiliation can transform into. Through their fascination and very impact, pioneers select others in their dream. They resuscitate their fantasies and get people to see empowering possible results for what's to come (J. M. Kouzes \& Posner, 2013).

Leader empowers facilitated exertion and manufacture vivacious gathering. They activity incorporate others. Pioneers fathom that common respect is what bolsters astounding undertakings. They try to make a situation of trust and human pride. They brace others, making each individual feel fit and astounding (Goewey, 2012).

Pioneers set up rule concerning the way people, companions, partners, and customers the equivalent, should be managed and the way wherein objective should be looked for after. They make significance standard and set a model for others to seek after, because the probability of complex change can over people and cover action they set between time targets so people can achieve little triumphs as they move toward tremendous objectives (Santamaría \& Santamaría, 2013).

Accomplishing amazing thing in affiliation is troublesome work. To keep desire and confirmation alive, pioneers see duties that individual make. In each triumphant gathering, the people need to participate in the prizes of their undertakings, so the pioneers recognize accomplishment. They make feel like holy people (Abba, Anumaka, \& Gaite, 2016).

The effect of leadership practices on association: The biggest and different work powers in the medicinal services framework are the Nurses. Nature of work life is a centrality of the medical caretakers where she can fulfill her own needs through a quality consideration to the patient's and accomplishing the hierarchical objectives. In nursing standpoint, Brooks characterize the nature of work life as "how much nursing authority can fulfill significant individual needs through their encounters in their work association while accomplishing the association's objectives" (Gayathiri, Ramakrishnan, Babatunde, Banerjee, \& Islam, 2013).

A need was likewise watched for nursing pioneers to reflect and self-assess their administration thinking about recognitions from the group on their received activities and practices, as the leadership rehearses are amazing markers of the presentation of crafted by the nursing group (Kvist, Tähkä, Ruotsalainen, \& Tervo-Heikkinen, 2014).

The planned role of leadership can be utilized to inspect on the best way to draw in authority models and use administration conduct to advance authoritative execution. The impalpable resources, for example, authority styles, culture, ability and fitness, and inspiration are key wellsprings of solidarity in firms that can consolidate individuals and forms and hierarchical execution (Khan, Bukhari, \& Channar, 2016).

\section{Scenario}

In study setting it is seen that the leaders are not notable with their job and set of working responsibilities and even not with power. There for their practices are very little successful. That is the reason they can't manage their sub ordinates in formal way. Other thing in perception is dependability which not pursued extraordinarily in general human services by pioneers. Then again pioneers are the good example for their sub ordinates if the pioneer didn't rehearse well clearly the sub ordinates embrace and performed in like manner. As per this circumstance it is sharp want to evaluate the authority rehearses in the Jinnah hospital. 
As of late, the issues of leadership practices have become significant subjects in all fields of work even in governmental issues and particularly in medicinal services areas. Nursing pioneers assume key job in molding the medical caretakers calling to be more receptive to changing human services framework than and just as become a good example for sub ordinaries. Successful leadership practices of social insurance experts are countable for reinforcing quality and reconciliation of care. Administration rehearses were seen as emphatically related with quality consideration (Sfantou et al., 2017).

Leaders who don't gauge quiet fulfillment need data on quality improvement, which may bring about diminished hierarchical execution (Kleefstra, Zandbelt, de Haes, \& Kool, 2015). The general business issue was that some emergency clinic pioneers who neglect to react to poor patient fulfillment reports may encounter lower authoritative execution (Bennister \& Heppell, 2016). Clinics with the most reduced fulfillment scores produce $21 \%$ more social insurance costs (Lieber et al., 2014).

\section{Conceptual framework}

Kouzes and Posner's (1987) model of leadership gave give sensible framework to this examination. They depict the five activity practices and ten social obligations that are associated with incredible pioneers. The authority practices are: trying the methodology, moving a shared vision, engaging others to act, exhibiting the way, and enabling the heart. The ten social obligations genuinely relate to the administration rehearses. The possibility of Kouzes and Posner's position model underscores that it is the star boss who dependably uses every one of the five leadership practices and ten direct obligations and transforms into an unprecedented pioneer (J. Kouzes \& Posner, 1987)

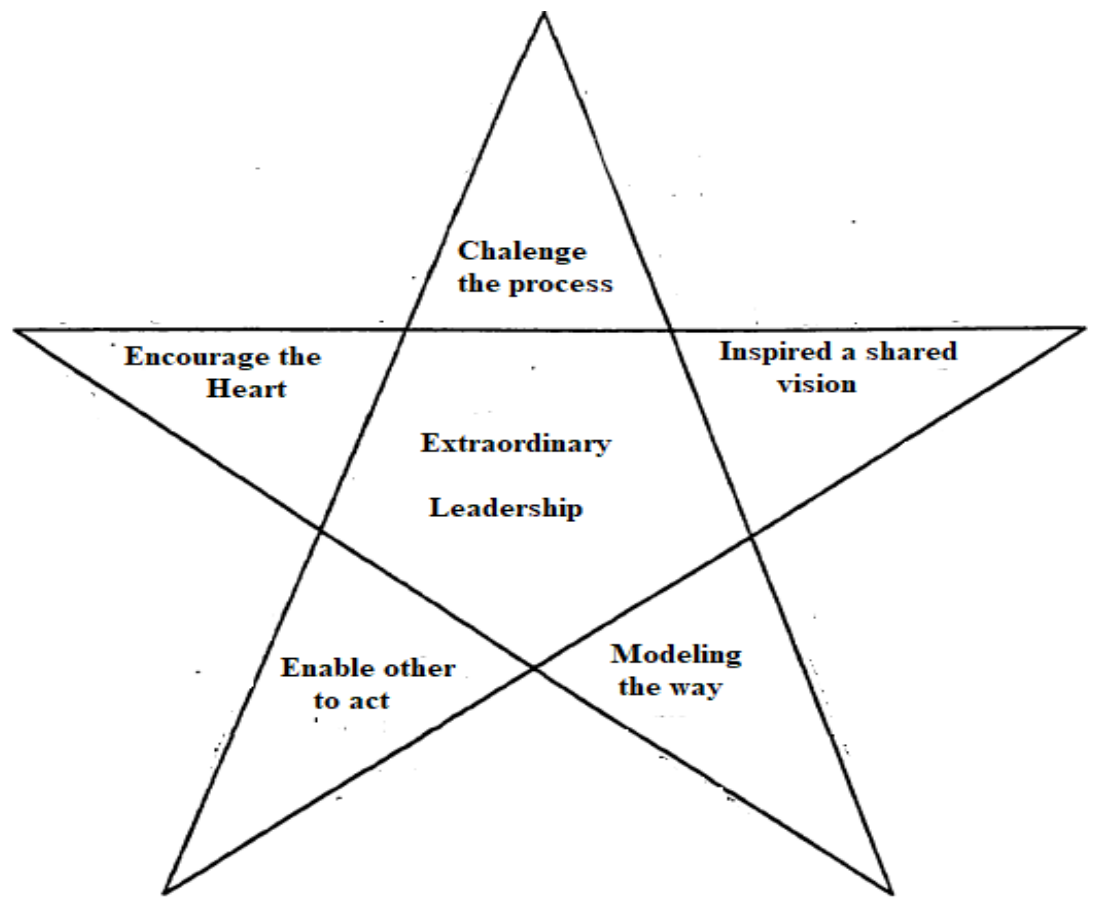

\section{Results}

Suggestions for Nursing Administration As this examination proposes, the chiefs, as saw without anyone else's input and their subordinates, respectably show uncommon authority rehearses. There is a requirement for nurture 
overseers to be perceptive of these practices and perceive that for unprecedented things to be cultivated in an association the five initiative practices must be displayed reliably. Consideration must be given to the present medical attendant director's development as pioneers. Current instructive planning is differed among the nurse supervisors. Choices about the future instructive level and planning expected of a first line nurture supervisor are vital for nurture directors to decide. The suggestions for future research because of these investigation discoveries are incredible. To start with, replication considers are expected to additionally approve and inspect study discoveries. Progressing estimation of the authority rehearses for the primary line nurture chiefs through self and subordinate appraisal would give significant knowledge into the acts of the principal line nurture trough and take into account continuous chances of development and reinforcing of the leadership practices.

Future scientists directing the authority rehearses study should practice alert in the quantity of subordinates per supervisor remembered for the examination. They would do well to decide various subordinates that would be an agent level of bite the dust supervisors to all the more likely encourage the exactness of the subordinate's view of the chief's authority rehearses.

\section{Discussion}

Shockingly the recognition is that this move is happening in Australia. In the most recent decade some first-line nurse directors have moved away from giving 'hands-on' quiet care. One reason is the acknowledgment of enrolled medical caretakers' independence in clinical work on following the exchange of attendant training into the tertiary segment. On the off chance that medical attendants are self-sufficient for their clinical practice, at that point ostensibly the requirement for directors to have master clinical information is limited. Moreover, medical caretakers expect their first-line nurture chiefs to invest more energy 'overseeing' and less on direct care with the goal that the attendants don't have to do as such (Drach-Zahavy, 2004).

Although much has been written about their evolving role, there is little consensus about what it should be (Duffield \& Franks, 2001). This outcomes, partially, from huge contrasts between singular social insurance frameworks. Also, the extent of the medical caretaker directors' job is to a great extent formed by the individual hierarchical structures in which they work, making examinations between first-line nurture supervisors by and large significantly progressively inconsistent (Willmot, 1998).

While it is conceivable to draw derivations about the jobs of first-line nurse administrators from the writing, it is significant not to make speculations regarding their jobs when making inferences about changes in their jobs and capacities. As an outcome of noteworthy authoritative change, medical caretakers are progressively set in noncustomary situations, for instance as business or human asset directors, office organizers, or arrangement investigators. At progressively senior levels, official medical attendants are regularly dependable for the expert needs of medical caretakers as well as for ethnic undertakings, advertising, showcasing, data and innovation. At an enormous showing Hospital in Sydney, the chief of the division of medical procedure is presently an attendant. While extended nursing jobs can be cheered as demonstrating that medical caretakers' aptitudes are esteemed and transferable (Mintzberg, 1994).

Then again, not withstanding this job extension raises two concerns. The first is that if the extended job of firstline nurse administrators incorporates non-nursing yet wellbeing orientated duties. In the event that attendants can oversee ethnic issues, for instance, at that point can a conventional administrator oversee medical caretakers and 
nursing? Changes to the board structures in the UK during the 1980 s recommend this is so (Meyer \& Dean, 1990).

The author contends that medical attendant supervisors in Australia have lost their attention on quality consideration. In the battle to create the executives abilities and build up themselves as directors they have relinquished a portion of their clinical believability. It is the workmanship and study of nursing that recognizes nurture chiefs from non-nurse administrators and legitimizes their authority (Meyer \& Dean, 1990).

A study led in 2014 with respect to leadership practices apparent by nurses and result uncovered that the seven out of 10 nursing staff held positive recognitions about authority morals and their expert improvement. Over one-third of nursing staff were disappointed with the nursing procedure and with their input and rewards, while just four out of 10 assessed their nursing chief either in a positive or negative manner. There were no critical contrasts with respect to their discernments when diverse foundation factors were considered (Kvist et al., 2014).

Related ponders it was found that it was anything but difficult to discuss leadership, however hard to practice (Lee, Smith, \& Cioci, 1993). The authors battled that turning into a remarkable pioneer was troublesome, however inside every chief is the ability to do as such. Creator distinguished that lacking instructive planning of medical attendant administrators has constrained their capacity to become astounding pioneers (Dugan, 2006).

Meighan (1990) likewise takes note of that medical caretaker chiefs are regularly ill-equipped to address the difficulty of remarkable initiative. The discoveries in this examination bolster these ideas (Meighan, 1990).

\section{References}

Abba, H., Anumaka, I., \& Gaite, S. (2016). Leadership practices and productivity of academic staff in polytechnics in Nigeria. American Journal of Academic Research, 1, A56-A68.

Bennister, M., \& Heppell, T. (2016). Comparing the dynamics of party leadership survival in Britain and Australia: Brown, Rudd and Gillard. Government and Opposition, 51(1), 134-159.

Clinton, H. R. (2017). What happened: Simon and Schuster.

Drach-Zahavy, A. (2004). Primary nurses’ performance: role of supportive management. Journal of advanced nursing, 45(1), 7-16.

Duffield, C., \& Franks, H. (2001). The role and preparation of first-line nurse managers in Australia: where are we going and how do we get there? Journal of Nursing Management, 9(2), 87-91.

Dugan, J. P. (2006). Explorations using the social change model: Leadership development among college men and women. Journal of college student development, 47(2), 217-225.

Ebersole, C. R., Alaei, R., Atherton, O. E., Bernstein, M. J., Brown, M., Chartier, C. R., . . Line, M. J. (2017). Observe, hypothesize, test, repeat: Luttrell, Petty and Xu (2017) demonstrate good science. Journal of Experimental Social Psychology, 69, 184-186.

Gayathiri, R., Ramakrishnan, L., Babatunde, S., Banerjee, A., \& Islam, M. (2013). Quality of work life-Linkage with job satisfaction and performance. International Journal of Business and Management Invention, $2(1), 1-8$.

Goewey, D. F. (2012). Examining the Kouzes and Posner leadership practices of elementary principals in central New York.

Keenan, A. M., Mutterback, E. E., Velthuizen, K. M., Pantalone, M. E., \& Gossack-Keenan, K. L. (2018). Perceptions of the effectiveness of Advanced Practice Nurses on a neurosurgery unit in a Canadian 
Tertiary Care Centre: A pre-and-post implementation design. International journal of nursing sciences, 5(2), 138-143.

Khan, R., Bukhari, A., \& Channar, Z. (2016). Effects of Leadership Style on Health Care Organizational Performance: A Survey of Selected Tertiary Care Hospital in Karachi, Pakistan. Int J Econ Manag Sci, $5(333), 2$.

Kleefstra, S. M., Zandbelt, L. C., de Haes, H. J., \& Kool, R. B. (2015). Trends in patient satisfaction in Dutch university medical centers: room for improvement for all. BMC health services research, 15(1), 112.

Kouzes, J., \& Posner, B. (1987). The Jossey-Bass management series. The leadership challenge: How to get extraordinary things done in organizations. San Francisco, CA, US: Jossey-Bass.

Kouzes, J. M., \& Posner, B. Z. (2013). Great leadership creates great workplaces: John Wiley \& Sons.

Kvist, T., Tähkä, K., Ruotsalainen, M., \& Tervo-Heikkinen, T. (2014). The impact of nursing leadership training on evidence-based leadership and practice. J Nurs Care, 3(181), 2167-1168.1000181.

Lee, V. E., Smith, J. B., \& Cioci, M. (1993). Teachers and principals: Gender-related perceptions of leadership and power in secondary schools. Educational Evaluation and Policy Analysis, 15(2), 153-180.

Lieber, S. R., Mantengoli, E., Saint, S., Fowler, K. E., Fumagalli, C., Bartolozzi, D., . . Bartoloni, A. (2014). The effect of leadership on hand hygiene: assessing hand hygiene adherence prior to patient contact in 2 infectious disease units in Tuscany. Infection Control \& Hospital Epidemiology, 35(3), 313-316.

McGrath, S. P., Taenzer, A. H., Karon, N., \& Blike, G. (2016). Surveillance monitoring management for general care units: strategy, design, and implementation. The Joint Commission Journal on Quality and Patient Safety, 42(7), 293-302.

Meighan, M. M. (1990). The most important characteristics of nursing leaders. Nursing Administration Quarterly, 15(1), 63-69.

Meyer, G. D., \& Dean, T. J. (1990). An upper echelons perspective on transformational leadership problems in high technology firms. The Journal of High Technology Management Research, 1(2), 223-242.

Mintzberg, H. (1994). The fall and rise of strategic planning. Harvard business review, 72(1), 107-114.

Santamaría, L. J., \& Santamaría, A. P. (2013). Applied critical leadership in education: Choosing change: Routledge.

Sfantou, D. F., Laliotis, A., Patelarou, A. E., Sifaki-Pistolla, D., Matalliotakis, M., \& Patelarou, E. (2017). Importance of leadership style towards quality of care measures in healthcare settings: a systematic review. Paper presented at the Healthcare.

Willmot, M. (1998). The new ward manager: an evaluation of the changing role of the charge nurse. Journal of advanced nursing, 28(2), 419-427. 